\title{
Tactile experience shapes prey-capture behavior in Etruscan shrews
}

\author{
Farzana Anjum and Michael Brecht* \\ Bernstein Center for Computational Neuroscience, Humboldt University, Berlin, Germany
}

\section{Edited by:}

Robyn Grant, University of Sheffield,

UK

\section{Reviewed by:}

D. Caroline Blanchard, University of Hawaii at Manoa, USA

Paul M. Nealen, Indiana University of Pennsylvania, USA

*Correspondence:

Michael Brecht, Bernstein Center for Computational Neuroscience, Humboldt University, Philippstrasse 13 Haus 6, Berlin 10115, Germany. e-mail:michael.brecht@

bccn-berlin.de
A crucial role of tactile experience for the maturation of neural response properties in the somatosensory system is well established, but little is known about the role of tactile experience in the development of tactile behaviors. Here we study how tactile experience affects prey capture behavior in Etruscan shrews, Suncus etruscus. Prey capture in adult shrews is a high-speed behavior that relies on precise attacks guided by tactile Gestalt cues. We studied the role of tactile experience by three different approaches. First, we analyzed the hunting skills of young shrews' right after weaning. We found that prey capture in young animals in most, but not all, aspects is similar to that of adults. Second, we performed whisker trimming for 3-4 weeks after birth. Such deprivation resulted in a lasting disruption of prey capture even after whisker re-growth: attacks lacked precise targeting and had a lower success rate. Third, we presented adult shrews with an entirely novel prey species, the giant cockroach. The shape of this roach is very different from the shrew's normal (cricket) prey and the thorax-the preferred point of attack in crickets-is protected by a heavy cuticle. Initially shrews attacked giant roaches the same way they attack crickets and targeted the thoracic region. With progressive experience, however, shrews adopted a new attack strategy targeting legs and underside of the roaches while avoiding other body parts. Speed and efficiency of attacks improved. These data suggest that tactile experience shapes prey capture behavior.

Keywords: whisker, vibrissa, experience, shrew, Suncus etruscus, object recognition

\section{INTRODUCTION}

The somatosensory system of mammals is a classic system for studying neural plasticity. Neurophysiological and anatomical analysis demonstrated that somatosensory cortical maps are highly plastic, both during development (Van der Loos and Woolsey, 1973; Simons and Land, 1987) and in adult animals (Buonomano and Merzenich, 1998). Neural plasticity can be induced by peripheral lesions, passive sensory experience, and training on sensory tasks. Much of the research on neural plasticity of the somatosensory system has focused on the rodent S1/barrel cortex (Woolsey and Van der Loos, 1970) and our knowledge about the neural mechanisms underlying the development of the somatosensory system is impressive (Feldman and Brecht, 2005).

While our knowledge of the development of barrel cortex physiology and anatomy is fairly detailed, we know less about the development of behavioral capacities and natural whiskermediated behaviors (Brecht, 2007). A notable exception is the work of Simons and colleagues (Carvell and Simons, 1995, 1996) that analyzed the perceptual consequences of barrel cortex plasticity. Specifically these authors demonstrated that whisker deprivation not only leads to alterations in neural responses but also is associated with a loss in tactile acuity in a texture discrimination task. Other author demonstrated that unilateral whisker trimming greatly impacts on behavioral lateralization (Meyer and Meyer, 1992; Aggestam and Cahusac, 2007) and that partial whisker removal can affect the bilateral synchrony of whisker movements (Sellien et al., 2005).

In the present work, we sought to study the role of experience in shaping biologically relevant tactile behaviors. To this end we analyzed the role of tactile experience in the prey capture behavior of the Etruscan shrews. Earlier work (Anjum et al., 2006) has shown that adult shrews capture very large prey in complete darkness. This behavior involves very fast and precise whiskerguided attacks. Experiments with artificial prey replica with Etruscan shrews and with the American water shrew, Sorex palustris (Catania et al., 2008) have shown that shape cues are sufficient triggers to initiate attacks.

In particular we posed the following questions: (1) how similar or different is the behavior of young shrews, at the time of weaning, in comparison to the adults? (2) How does whisker deprivation in the first weeks of life affect prey capture in adult shrews? (3) Are adult shrews capable of adapting to a novel prey?

We find that tactile experience has a profound influence on prey capture behavior and that even adult shrews can adopt entirely novel prey capture strategies.

\section{MATERIALS AND METHODS ETRUSCAN SHREWS}

Capture, handling, and maintenance of Etruscan shrews have been described in detail before (Anjum et al., 2006). Data 
presented here refer to 18 animals (four females, 14 males; four wild captures, 14 captive born in our colony). Etruscan shrews were captured under a permit of the local government (permit no. N 6085/T-A31, Firenze, Italy) in the provinces Firenze and Livorno and all our procedures complied with German regulations on animal welfare and were approved by an ethics committee.

\section{PREY}

\section{Crickets}

Crickets were obtained from a local vendor (Gekonia, Berlin). We fed mainly juvenile and adult specimen of two cricket species, field crickets (Gryllus assimilis), and house crickets (Acheta domesticus). They were maintained in our facility in a temperature regulated room and fed with fruit, salad leaves, and vitamin-fortified dry fish food.

\section{Giant cockroaches}

The giant cockroach, Blaberus giganteus, is naturally found in the rainforests of South America. Giant cockroaches were bred and housed in glass terrariums with soft wood bedding and egg crates for hiding. They were maintained on fruits, lettuce, dry fish, and dog food, and supplied with water. We used the juveniles, about fourth instar larval stage. The body lengths were between 1.5 and $3.0 \mathrm{~cm}$ and thus matched the size of crickets normally fed to the shrews.

The giant roach larvae used in our experiments are burrow in soil and are only found in humid rainforests of South America. They are quite different in appearance from the common cockroach larvae to our knowledge quite different from insects found in shrew habitat in Italy. Since we do not know the detailed prey history of our wild-trapped shrews, we cannot exclude that they encountered somewhat similar prey before. The data shown in the result section argue against this idea, however. Both wild-trapped shrews and captive-bred shrew improved in hunting efficiency after experience with giant cockroaches.

The mass of crickets and giant cockroaches overlapped and ranged from 0.5 to $2 \mathrm{~g}$. In size (body-length) matched animals' crickets were about $20 \%$ heavier. Besides crickets and roaches we fed animals also on mealworms (larvae of the mealworm beetle, Tenebrio molitor). Mealworms were occasionaly supplied as an alternative to crickets and were given to breeding females as a source of fat. Animals were fed between 1 and $2 \mathrm{~h}$ prior to dimming of the lights every day and typically received slightly more cricket/mealworms than they would consume. The only exception from this ad libitum regime was made with animals that were presented with giant cockroaches. These animals were presented with giant cockroaches and after filming these encounters they received an additional five mealworms per day. This regime was chosen to increase the motivation to hunt giant cockroaches.

\section{YOUNG SHREWS}

Shrews were weaned at postnatal day 21-23. The whole litter was moved into a new terrarium and animals were filmed from the very first day of weaning. Crickets were offered in an arena (measuring $12 \times 12 \mathrm{~cm}$ ) and also in the terrarium.

\section{WHISKER REMOVAL}

After birth whiskers of the young animals were trimmed every other day. All pups of a litter were briefly removed from the parents' terrarium. In half of the animals whisker trimming (all whiskers) was done by restraining/holding the animals firmly by the neck muscles and cutting the whiskers very close to the skin with a sharp pair of small spring scissors using magnifying glasses for a better view. The other half of the litter (the control animals) was handled and held the same way for similar lengths of time, except that the whiskers were not cut. The weights of the pups were noted on every occasion of whisker trimming and their weight gain was comparable to that of the controls. Litters in which we performed whisker removal, were weaned slightly later than normal at postnatal day P25 and whiskers were trimmed for the last time on the day of weaning. Whisker deprived animals and control animals were housed separately but received the same number and similar sized crickets and mealworms (larvae of the mealworm beetle, T. molitor) for the next 4 weeks. Animal were filmed 4 weeks later; at this time whiskers were fully regrown. Whisker re-growth was assessed under the microscope and documented by photographs (Figure 3A).

\section{EXPERIENCE WITH NOVEL PREY}

In the experiments relating to novel prey, we housed animals individually and carefully monitored every single prey encounter. To this end giant cockroaches were offered in an arena $(7.5 \times$ $7.5 \mathrm{~cm}$ ), one at a time and all encounters were videotaped under infrared illumination. Five shrews (four wild captured, one captive born from our colony) were used for this experiment. Shrews were regarded as "naïve" during their initial encounters with roaches. Therefore, the data from the first 4-6 roaches that were captured were termed "naïve." Animals were considered to be "experienced," when they had captured over 50 roaches over a period of at least 8 weeks. Because animals required several attacks to capture/kill a giant cockroach, all "experienced" shrews had placed several hundred attacks on giant cockroaches.

\section{VIDEO RECORDINGS, ANALYSIS, AND CLASSIFICATION OF ATTACKS}

Videotaping and frame-by-frame analysis have been described in detail before (Anjum et al., 2006). In brief, encounters with prey were staged in custom-made acrylic arenas and videotaped in complete darkness using infrared illumination with an infrared sensitive video camera. The Scion Image (version 1.63) software was used for frame-by-frame analysis of attack clips. The shrew's approach toward the prey, which was followed by a rapid protraction of its rostrum toward the cricket resulting in a putative bite was counted as a completed attack. Aborted attacks started off in the same way, the shrew approached the prey, got as close as $0.5 \mathrm{~cm}$ or closer but did not make rapid protractions of the rostrum, therefore not biting the insect. Aborted attacks occurred either because the crickets were successful in escaping or because the shrew did not strike.

\section{RESULTS}

\section{PREY CAPTURE IN YOUNG SHREWS}

Shrew pups weaned between P21 and P23 were capable of hunting independently. 


\section{Attack histograms}

Prey captures in shrews are complex chains of events. To develop a quantitative grip on prey capture behavior, we derived measurements from a very large number of attacks. As described previously (Anjum et al., 2006), we first determined in a frameby-frame-analysis of attack video, the endpoint of each attack and noted to which of nine cricket body parts attacks were directed. Accordingly, the cricket body was divided into nine parts, legs, cerci, posterior-, medial-, and anterior abdomen, posterior- and anterior thorax, head, and the antennae. The data were displayed as attack histograms (Figure 1). The attack histogram of adults (Figure 1A) showed that almost three quarters of attacks targeted the thorax (358 of a total of 456 attacks). Young animals also showed a tendency to attack the thorax (Figure 1B), but the preference was not as strong as adults. The number of attacks on the thorax (144 attacks) was about the same in number as the attacks on the remaining body parts (155 attacks). The fraction of attacks placed on the tho$\operatorname{rax}(79 \%)$ in adults was significantly different from the fraction of thorax attacks (48\%) in young animal (Fisher's exact test,

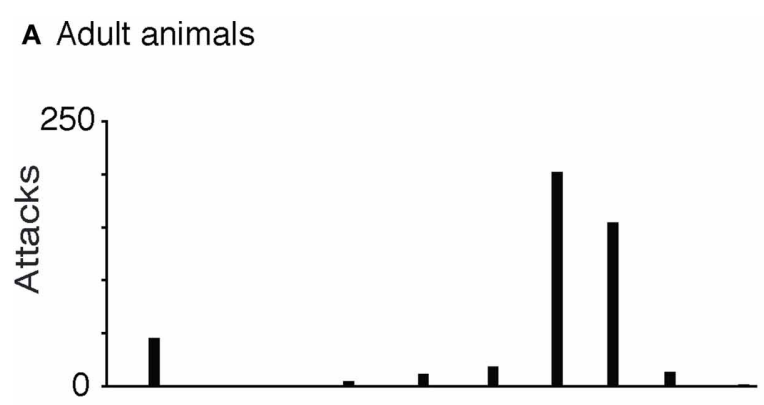

B Young animals

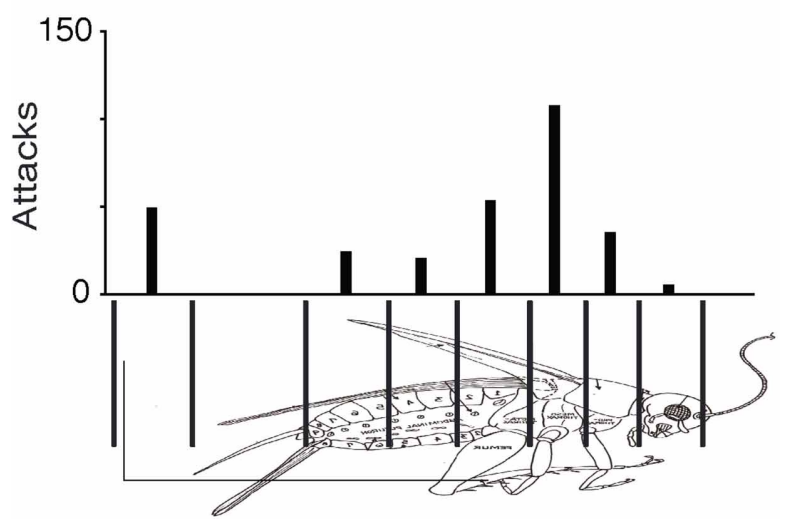

FIGURE 1 | Comparison of attack histograms in adult and young shrews. (A) Histogram of adult shrew attacks over nine body parts. About three quarters of (358 of a total of 456) attacks targeted the thorax. (B) Histogram of young (directly after weaning) shrew attacks over nine body parts. Young shrews also attack preferentially the thorax but the preference is less strong than that in adults. The fraction of attacks placed on the thorax (79\% of 456 attacks) in adults was significantly different from the fraction of thorax attacks (48\% of 300 attacks) observed in young animals (Fisher's exact test, two-tailed, $p<0.0001$ ). two-tailed, $p<0.0001)$. Unlike adults young animals placed a large number of attacks (18\% of total attacks) on the anterior abdomen.

\section{Completed and aborted attacks}

Young animals also have a similar success rate, i.e., similar and statistically not different (Fisher's exact test, two-tailed, $p>0.7$ ) fraction of aborted attacks and completed attacks (Figure 2A).

\section{Repeated attacks}

Adult shrews have the tendency to repeatedly attack the same cricket and even on the same body part of the cricket, supposedly using short-term memories of prior attack positions to guide further attacks (Anjum et al., 2006). Apparently this was a more efficient way of hunting as the prey that was attacked more often and recurrently, without getting time to recover from the trauma of the previous attack could be immobilized faster. In Figure $\mathbf{2 B}$ we show the number of immediately successive attacks shrews would place on a specific cricket. On average the adults would place 3.2 attacks on each cricket they initiated a first attack on, significantly more than young

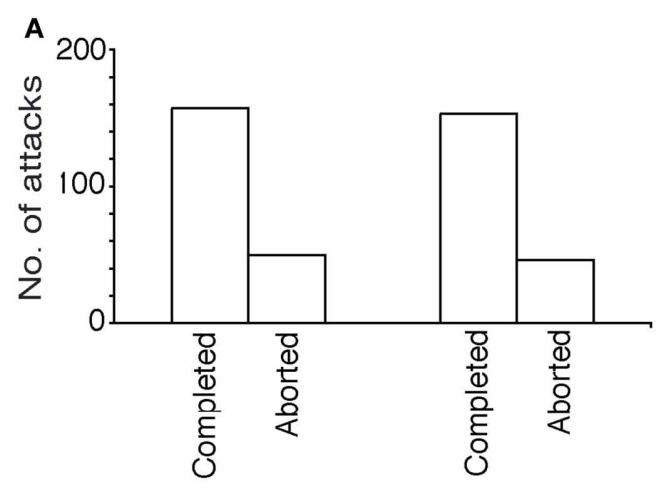

Adult animals Young animals

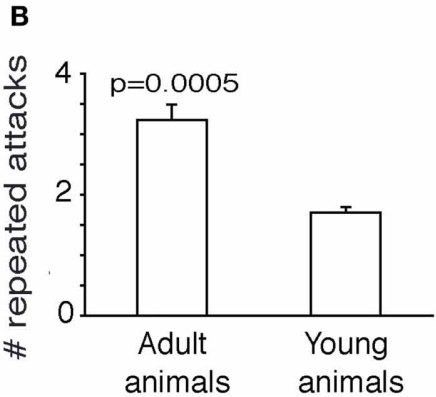

FIGURE 2 | Further attack characteristics in adult and young shrews. (A) Comparison of aborted and completed attacks in adult and young animals. The fraction of aborted and completed attacks in adult and young animals was not significantly different (Fisher's exact test, two-tailed, $p>0.7$ ). (B) Repeated attacks (attacks that immediately follow one-another without intervening breaks or attacks on other prey animals). Adult animals attacked the same cricket repeatedly more often than the young animals. The number of repeated attacks in was significantly higher adult than young animals [ $n=209$ first attacks (adults) vs. 202 first attacks (young animals), unpaired $t$-test, two-tailed, $p<0.0005$. 
shrews, who placed only 1.5 attacks on each cricket they initiated a first attack on $[n=209$ (adults) vs. 202 (young animals), unpaired $t$-test, two-tailed, $p<0.0005]$. The number of repeated attacks increases with the persistence with which a shrew attacks a specific prey animal; apparently young shrews more easily lose track of their prey or get more easily distracted by other prey.

\section{Cricket size}

The prey capture behavior of the young shrews also seems to differ from the adults in the size of the crickets that they prefer to attack. Young animals preferentially attacked smaller crickets $(1.5-1.75 \mathrm{~cm})$ and preferentially left larger crickets $(\geq 2 \mathrm{~cm})$ behind (data not shown). Adults, in contrast, attacked crickets of all sizes (data not shown).

\section{WHISKER DEPRIVATION}

Whisker trimming leads to severe deficits in prey capture in adult shrews (Anjum et al., 2006). In the context of the present study we wanted to determine how the lacks of whisker experience in early life affects prey capture capabilities. To this end we trimmed whiskers for 3-4 weeks and then allowed them to regrow. Figure 3A shows comparison between the whiskers of an untrimmed control animal (left), a whisker-trimmed animal at the end of the deprivation period (Figure 3A middle) and the same animal after whisker-regrowth (Figure 3A right). There was no visible difference in the vibrissae of the control animal or the deprived animal with fully re-grown whiskers.

\section{Attack histograms}

In spite of the vibrissae of the deprived animals re-growing to normal lengths and distribution, whisker-deprived animals performed poorly in prey capture. Compared to controls (Figure 3B) whisker-deprived animals lacked the precise targeting of attacks to the thorax (Figure 3C). In whisker-deprived animals, attacks were more or less evenly distributed over the entire cricket body and only $22 \%$ (101 out of 459 ) of attacks targeted the thorax. The fraction of attacks placed on the thorax (79\% of 456 attacks) in control adults was significantly higher in controls than the fraction of thorax attacks (22\% of 459 attacks) in deprived animals (Fisher's exact test, two-tailed, $p<0.0001$ ).

\section{Completed and aborted attacks}

The success rate of attacks was markedly lowered by whiskerdeprivation. In controls only $32 \%$ of attacks were aborted and the remainder was completed. In contrast in whisker-deprived animals 57\% of attacks were aborted (Figure 4A) and this difference was significant (Fisher's exact test, two-tailed, $p<0.05$ ).

\section{Repeated attacks and cricket size}

The controls attacked each cricket repeatedly, on an average 3.2 consequent attacks on the same cricket while the test animals did only two times (Figure 4B) (unpaired $t$-test, two-tailed $p=0.0004)$. There was no significant difference in the size of the crickets attacked between the controls and test animals (data not shown).
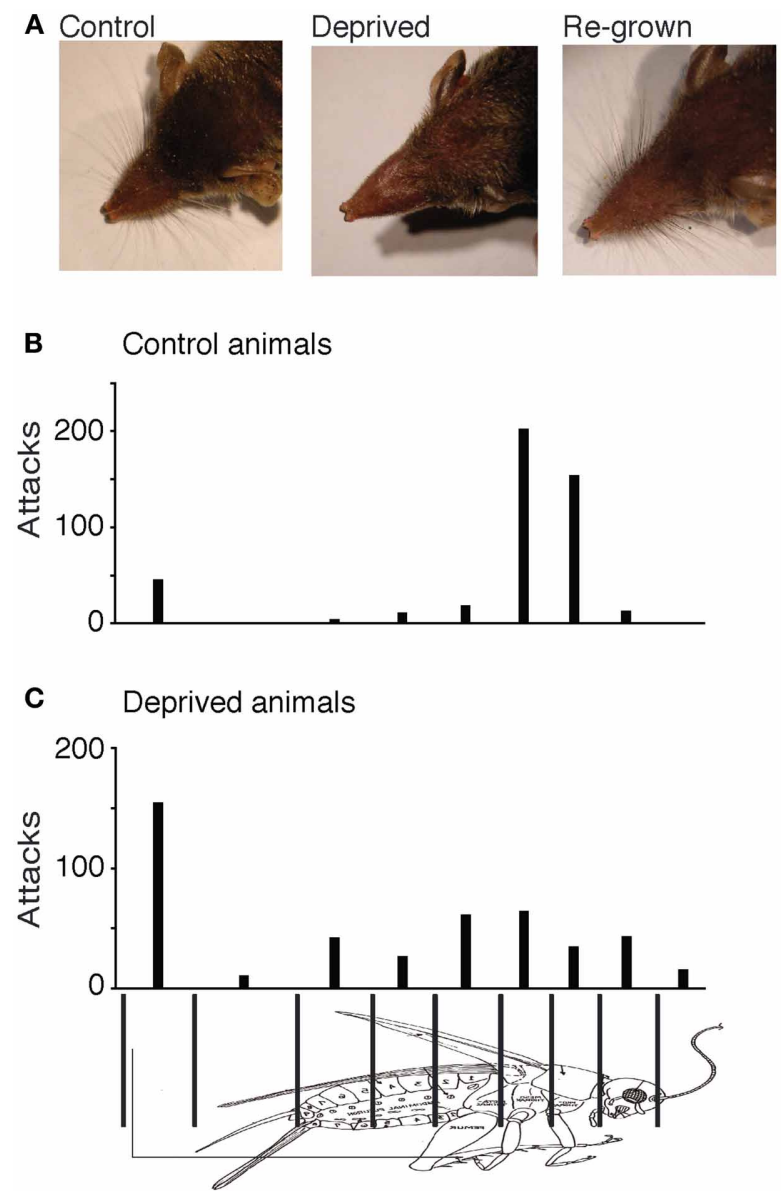

FIGURE 3 | Whisker deprivation. (A) Comparison between the whiskers of an untrimmed control animal (left), a whisker-trimmed animal at the end of the deprivation (middle) and the same animal after whisker-regrowth (right). (B) Attack histogram of control animals. (C) Attack histogram of deprived animals (after whisker regrowth). The fraction of attacks placed on the thorax (79\% of 456 attacks) in control adults was significantly different from the fraction of thorax attacks ( $22 \%$ of 459 attacks) observed in deprived animals (Fisher's exact test, two-tailed, $p<0.0001$ ).

\section{EXPERIENCE WITH NOVEL PREY}

When shrews were first exposed to the novel prey specimenthe giant cockroach-they did not attack giant roaches. Only after exposing the shrews to giant roaches for 3-8 days at their regular feeding times the shrews placed their first attack attempts on roaches.

\section{Attack histograms}

The giant cockroach differs in important ways from the shrew's normal cricket prey (Figure 5A). It has a very tough cuticle all over the dorsal surface of the body, but has a much softer/tender ventral side. Its appendages, namely the cerci, legs, and antennae and even the head are somewhat placed below this shield-like cuticle. Only a part of the posterior legs and antennae can be found to be sticking out of the body making it difficult for the shrews to get a grip/be able to bite. 

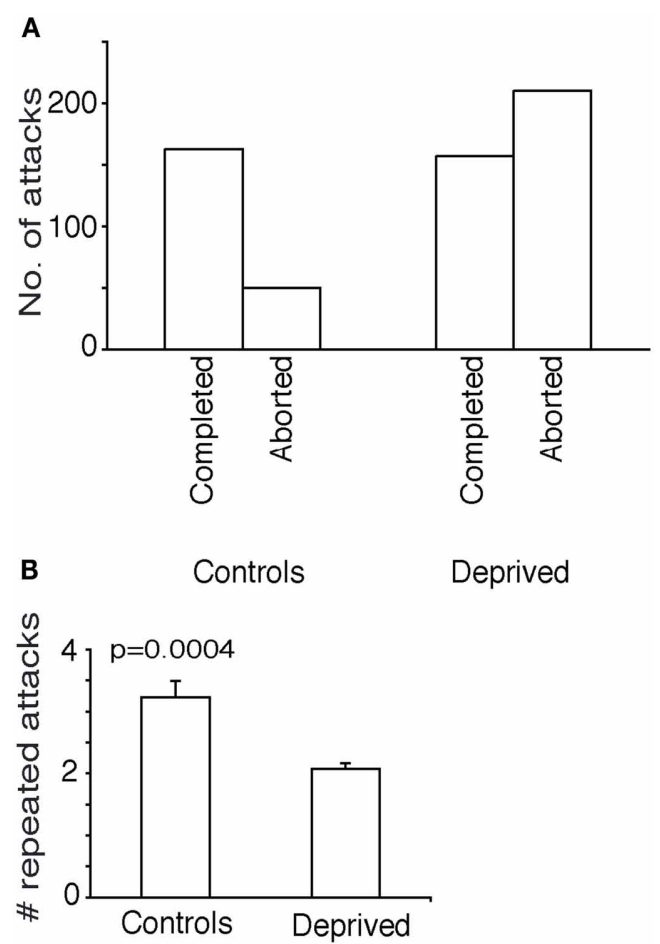

FIGURE 4 | Further attack characteristics in whisker deprived animals (A) Counts of aborted and completed attacks/success rate. In controls only $32 \%$ of attacks were aborted. In whisker-deprived animals $57 \%$ of attacks were aborted. (B) Repeated attacks. Control animals attacked the same cricket repeatedly more often than the deprived animals.

When first exposed to a giant roach, shrews attacked it with a similar pattern as they placed attacks on crickets. The attack histogram in Figure 5B shows data pooled from five inexperienced shrews. Of the 815 analyzed attacks, 521 were placed on the body (64\%) and 294 on the legs and underside. A large portion of the attacks on the body were on the anterior body of the roach, similar to the attack pattern that normal shrews show for crickets. After experience with more than 50 roaches, the attack pattern radically changed. Now the same shrews attacked the body less and legs and under side more often (Figure 5C). Of the 756 attacks analyzed, only 106 were on the body (14\%), and 650 on the legs and body. The change in distribution of on body- vs. non-body directed attacks in naïve vs. experienced animals was highly significant (Fisher's exact test, two-tailed $p<0.0001)$.

\section{Completed and aborted attacks}

Early after the exposure to the new insect, shrews were quite unsuccessful in their attempts to attack the giant roaches and 62\% of the attacks were aborted (Figure 6A). With experience, shrews became more efficient and only $33 \%$ of attacks were aborted.

\section{Attack durations}

The increase in efficiency of attacks with experience also reflected in a decrease of the time required for immobilizing and picking up the roach (Figure 6B). The time taken by each naive shrew
A

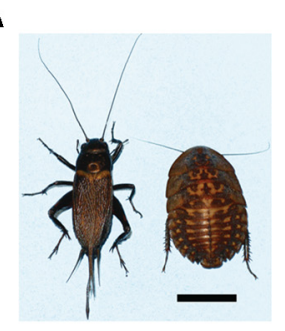

B Naive animals

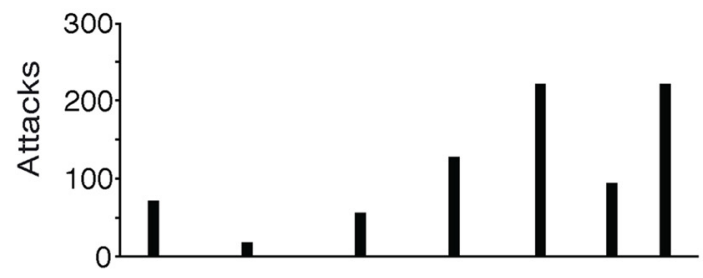

c Experienced animals

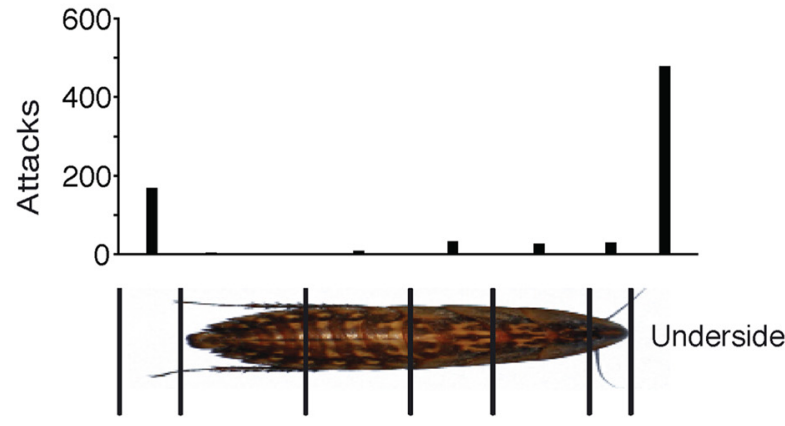

FIGURE 5 | Effect of experience with novel prey. (A) Cricket and giant roach differ in shape strikingly. The bottom right scale bar equals $1 \mathrm{~cm}$. (B) Attack histogram of Naïve animals showing $67 \%$ of all attacks on the body. (C) Attack histogram of experienced animals showing a change in attack strategy with only $14 \%$ attacks on the body.

(in seconds) is shown to reduce with experience. All reductions in time taken to pick up the roach were found to be significant.

\section{Paw-use}

In the initial attacks of shrews on the giant roaches, the shrews displayed attack behaviors not commonly seen in attacks on crickets. Specifically the shrews used one or both of their forepaws in attacks on roaches. This behavior disappeared with progressive experience. In Figure 6C, a comparison of frequency of pawusage before and after experience is shown. Before experience, shrews used the paw in $40 \%$ of the attacks and after experience only $7 \%$ of the attacks employed the paw.

\section{DISCUSSION}

Three lines of evidence presented here suggest that shrew tactile behaviors are not hardwired, but are modified by tactile experience. First, the hunting behavior of young animals differs in subtle but significant ways from the hunting behavior of adults. Second, postnatal whisker deprivation has devastating effects on 


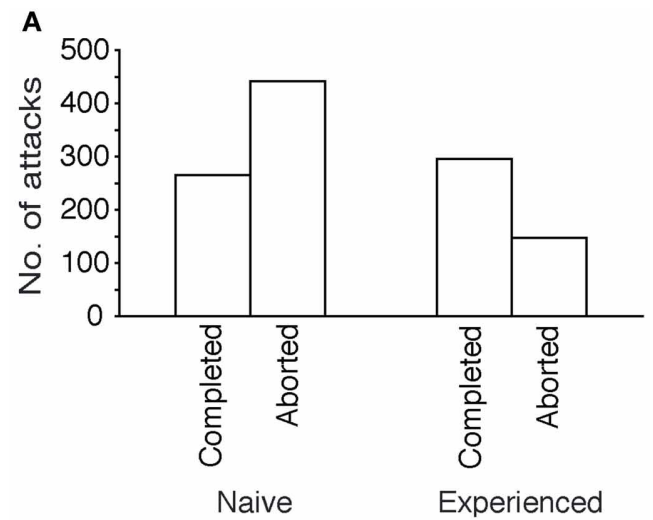

B

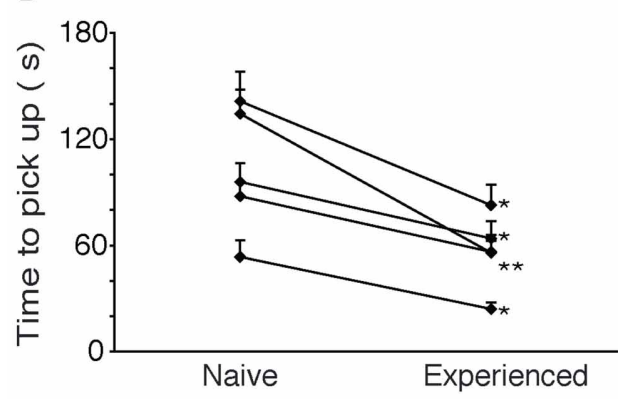

C

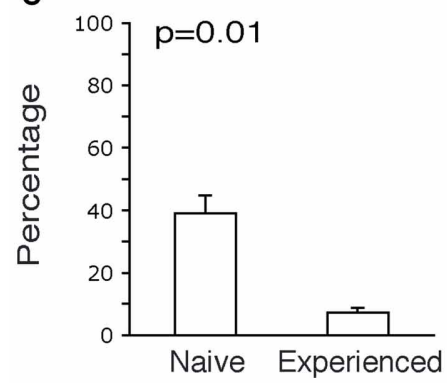

FIGURE 6 | Further characteristics of attacks on novel and familiar prey. (A) Comparison of success rate between Naïve and experienced animals. Naïve animals had $62 \%$ attacks aborted but after experience only $33 \%$ attacks aborted. (B) Attack durations. After experience all animals show a significant reduction in time taken to pick a roach (paired $t$-tests, two-tailed, $p<0.05$ ). (C) Paw use. Naïve animals used the fore paw in $40 \%$ of the attacks. Experienced animals used the fore paw in only $7 \%$ of the attacks.

the shrews' hunting capabilities. Third, we find that adult shrews are able to radically alter their prey capture strategies in response to novel prey.

\section{YOUNG ANIMALS}

The prey capture behavior of young shrews directly after weaning was largely similar to the adults. The young animals attacked the anterior abdomen more often than the adults thereby demonstrating a slight lack of precision in targeting. Further experience with attacking crickets might improve attack precision. Moreover young shrews pursue individual crickets less persistently than adult shrews do. Again this change in attack strategy might come about by additional experience.
The similarity of prey capture behavior of young shrews after weaning and adults may be viewed as evidence that tactile experience is not required for prey capture behaviors. An alternative interpretation, which seems more consistent with our other findings (in particular the deprivation data), is that shrews already may have acquired considerable tactile experience prior to weaning. There are other behaviors, like nest building in female rats (Nováková, 1977), which are known to be partially acquired. Females that were prematurely weaned, there by deprived of early experience, nested, and handled the young differently from those weaned normally. As early as P14, the shrew pups have been seen moving about the cages along with the parents. According to our informal observations pups have been spotted tugging at a cricket, more likely hunted by the parents. Perhaps such experience acquired already in the nest contributed to the advanced hunting abilities of young animals directly after weaning. Young shrew may also acquire tactile experience through social behaviors in the nest such as play-fighting. It is not known if and to what extent shrews' play-fight, but in rats this behavior relies on tactile cues (Siviy and Panksepp, 1987) and there is evidence pointing to a role of somatosensory cortex in play-fighting (Panksepp et al., 1994).

\section{WHISKER DEPRIVATION IN EARLY LIFE}

The strong effects that whisker deprivation in the early post natal life has on the prey capture behavior indicates that shrews could be actually acquiring/learning prey capture skills, that may account for the pups accompanying parents on hunting expeditions at nightfall (in shrew rooms). We analyzed prey capture behavior soon after their vibrissae regained their normal lengths. The effects were very similar to those in adult-vibrissae-deprived shrews (Anjum et al., 2006) in diminished precision/attack targeting, and reduced rates of successful attacks. There are known to be critical periods in rats (Simons and Land, 1987; Fox, 1992) and mice (Van der Loos and Woolsey, 1973; Weller and Johnson, 1975) during neonatal life when deprivation of tactile experience/whiskers leads to lasting effects even after months of experience with regrown whiskers. In shrews, the critical period of learning from tactile experience could be in early post natal life/through out the first 3 weeks after birth, which the pups spend growing with their parents. Etruscan shrews are known to have a life span between 1 and 1.5 years. One month long experience with regrown whiskers was insufficient to gain normal hunting skills of an adult.

\section{NOVEL PREY}

The shrews attacked roaches initially in the same way they attack the crickets. Later, however, they adopted a new strategy: they attacked the legs and flipped the roach onto it's back and attacking the soft underside immobilizing it/making it defenceless. This change in strategy markedly increased the efficiency of attacks on the new prey. Our results imply that adult shrews are able to learn new behaviors through continued contact/interaction with a novel prey. All five shrews displayed the same change in the strategy; the most effective way of attacking a roach. The ability of Etruscan shrews to adapt to a new prey and the ability to 
implement novel prey capture strategies could be highly adaptive in environments with changing prey populations.

\section{THE ROLE OF WHISKERS IN ATTACK BEHAVIORS}

Our findings on the role of shrew whiskers in prey capture go well with a large body of literature suggesting a more general role of whiskers in attacks and aggressive behaviors. In rats whisker are required in attacks on mice (Thor and Ghiselli, 1975), play a significant role in controlling maternal aggression (Kolunie and Stern, 1990) and both in aggressive and non-aggressive social behaviors (Thor, 1976; Blanchard et al., 1977; Sarna et al., 2000; Brecht and Freiwald, 2011; Wolfe et al., 2011).

\section{THE ROLE OF EXPERIENCE IN THE SOMATOSENSORY SYSTEM}

Our finding that shrew tactile behaviors are modified by tactile experience is in line with a large body of work on the ontogeny of the rodent somatosensory systems (Feldman and Brecht, 2005). Specifically, we hypothesize that the large primary somatosensory cortices of nocturnal rodents like rats and mice (Welker, 1971; Brecht and Freiwald, 2011), Etruscan shrews (Roth-Alpermann et al., 2010) as well of other shrew species (Catania et al., 1999) might serve as repositories for tactile learning. Numerous neurophysiological studies have demonstrated that whisker deprivation both in young and adult rodents can rapidly alter neuronal response properties. As far as available, the behavioral evidence (Carvell and Simons, 1995) also indicated performance on tactile tasks is compromised by disrupted tactile experience. Brief periods of altered sensory experience in

\section{REFERENCES}

Aggestam, F., and Cahusac, P. M. (2007). Behavioural lateralization of tactile performance in the rat. Physiol. Behav. 91, 335-339.

Anjum, F., Turni, H., Mulder, P. G., van der Burg, J., and Brecht, M. (2006). Tactile guidance of prey capture in Etruscan shrews. Proc. Natl. Acad. Sci. U.S.A. 103, 16544-16549.

Bender, K., Allen, C. B., and Feldman, D. E. (2006). Synaptic basis for deprivation-induced synaptic weakening in rat somatosensory cortex. J. Neurosci. 26, 4155-4165.

Blanchard, R. J., Takahashi, M. K., Fukunaga, K. K., and Blanchard, D. C. (1977). Functions of the vibrissae in the defensive and aggressive behavior of the rat. Aggr. Behav. 3, 231-240.

Brainard, M. S., and Doupe, A. J. (2002). What songbirds teach us about learning. Nature 417, 351-358.

Brecht, M. (2007). Barrel cortex and whisker-mediated behaviors. Curr. Opin. Neurobiol. 17, 408-416.

Brecht, M., and Freiwald, W. A. (2011). The many facets of facial interactions in mammals. Curr. Opin. Neurobiol. 22, 259-266.
Buonomano, D. V., and Merzenich, M. M. (1998). Cortical plasticity: from synapses to maps. Annu. Rev. Neurosci. 21, 149.

Carvell, G. E., and Simons, D. J. (1995). Task- and subject-related differences in sensorimotor behavior during active touch. Somatosens. Mot. Res. 12, 1-9.

Carvell, G. E., and Simons, D. J. (1996). Abnormal tactile experience early in life disrupts active touch. J. Neurosci. 16, 2750-2757.

Catania, K. C., Hare, J. F., and Campbell, K. L. (2008). Water shrews detect movement, shape and smell to find prey underwater. Proc. Natl. Acad. Sci. U.S.A. 105, 571-576.

Catania, K. C., Lyon, D. C., Mock, O. B., and Kaas, J. H. (1999). Cortical organization in shrews: evidence from five species. J. Comp. Neurol. 410, 55-72.

Diamond, M. E., Armstrong-James, M., and Ebner, F. F. (1993). Experiencedependent plasticity in adult rat barrel cortex. Proc. Natl. Acad. Sci. U.S.A. 90, 2082-2086.

Feldman, D. E., and Brecht, M. (2005). Map plasticity in somatosensory cortex. Science 310, 810-815.

Fox, K. (1992). A critical period for experience dependent plasticity in

adult rats have shown to bring about significant changes in the functional properties of the S1 neurons (Diamond et al., 1993). We have rich information about the neuronal consequences of whisker deprivation. Specifically we know that whisker deprivation leads to massive alterations in the primary somatosensory cortex. At the same time we know little to nothing about the neural mechanism that represent more subtle changes in experience like the knowledge of a novel prey specimen. It remains to be seen if such knowledge is also reflected with changes of response properties in primary somatosensory cortex, or if such knowledge leads to alterations in higher-order processing stations as suggested from studies in the visual system (Logothetis et al., 1995).

\section{CONCLUSION}

Our results on the tactile behaviors in Etruscan shrews resemble experience-dependence of visual behaviors in cats or monkeys. Visual experience plays an important role in the maturation of the visual system (Hubel and Wiesel, 1970; Hensch, 2004). Similarly, auditory behaviors like song-learning in birds have been shown to depend on experience (Brainard and Doupe, 2002). It is important to note, however, that - even in vertebrates - not all behaviors that require complex sensorimotor integration require experience. For example, electrosensory system of some electric fish seems to be largely hardwired (Viete and Heiligenberg, 1991). Etruscan shrews display some of the most sophisticated tactile behaviors known to date (Anjum et al., 2006) and our present results suggest that these behaviors are shaped by experience.

somatosensory cortex. J. Neurosci. $12,1826-1838$.

Hensch, T. K. (2004). Critical period regulation. Annu. Rev. Neurosci. 27, 549-579.

Hubel, D. H., and Wiesel, T. N. (1970). The period of susceptibility to the physiological effects of unilateral eye closure in kittens. J. Physiol. 206, 419-436.

Kolunie, J. M., and Stern, J. M. (1990). Maternal aggression: disruption by perioral anesthesia in lactating Long-Evans rats (Rattus norvegicus). J. Comp. Psychol. 104, 352-360.

Logothetis, N. K., Pauls, J., and Poggio, T. (1995). Shape representation in the inferior temporal cortex of monkeys. Curr. Biol. 5, 552-563.

Meyer, M. E., and Meyer, M. E. (1992). The effects of bilateral and unilateral vibrissotomy on behavior within aquatic and terrestrial environments. Physiol. Behav. 51, 877-880.

Nováková, V. (1977). Significance of the weaning period for natality and maternal behaviour of laboratory rats. Physiol. Bohemoslov. 26, 303-309.

Panksepp, J., Normansell, L., Cox, J. F., and Siviy, S. M. (1994). Effects of neonatal decortication on the social play of juvenile rats. Physiol. Behav. 56, 429-443.

Roth-Alpermann, C., Anjum, F., Naumann, R., and Brecht, M. (2010). Cortical organization in the Etruscan shrew (Suncus etruscus). J. Neurophysiol. 104, 2389-2406.

Sarna, J. R., Dyck, R. H., and Whishaw, I. Q. (2000). The Dalila effect: C57BL6 mice barber whiskers by plucking. Behav. Brain Res. 108, 39-45.

Sellien, H., Eshenroder, D. S., and Ebner, F. F. (2005). Comparison of bilateral whisker movement in freely exploring and head-fixed adult rats. Somatosens. Mot. Res. 22, 97-114.

Simons, D. J., and Land, P. W. (1987). Early experience of tactile stimulation influences organization of somatic sensory cortex. Nature 326, 694.

Siviy, S. M., and Panksepp, J. (1987). Sensory modulation of juvenile play in rats. Dev. Psychobiol. 20, 39-55.

Thor, D. H. (1976). Enhanced social docility in male hooded rats by dermal cautery of the vibrissal pads. Aggr. Behav. 2, 39-53.

Thor, D. H., and Ghiselli, W. B. (1975). Suppression of mouse 
killing and apomorphine induced social aggression in rats by local anesthesia of the mystacial vibrissae. J. Comp. Physiol. Psychol. 88, 40-46.

Van der Loos, H., and Woolsey, T. A. (1973). Somatosensory cortex: structural alterations following early injury to sense organs. Science 179, 395.

Viete, S., and Heiligenberg, W. (1991). The development of the jamming avoidance response (JAR) in Eigenmannia: an innate behavior indeed. J. Comp. Physiol. A 169, 15-23.
Welker, C. (1971). Microelectrode delineation of fine grain somatotopic organization of $(\mathrm{SmI})$ cerebral neocortex in albino rat. Brain Res. 26, 259-275.

Weller, W. L., and Johnson, J. I. (1975) Barrels in cerebral cortex altered by disruption in newborn but not five-day old mice (Cricetidae and Muridae). Brain Res. 83, 504-508.

Wolfe, J., Mende, C., and Brecht, M. (2011). Social facial touch in rats. Behav. Neurosci. 125, 900-910.

Woolsey, T. A., and Van der Loos, H. (1970). The structural organization of layer IV in the somatosensory region (SI) of mouse cerebral cortex. The description of a cortical field composed of discrete cytoarchitectonic units. Brain Res. 17, 205-242.

Conflict of Interest Statement: The authors declare that the research was conducted in the absence of any commercial or financial relationships that could be construed as a potential conflict of interest.

Received: 09 March 2012; paper pending published: 29 March 2012; accepted:
28 May 2012; published online: 12 June 2012.

Citation: Anjum F and Brecht M (2012) Tactile experience shapes prey-capture behavior in Etruscan shrews. Front. Behav. Neurosci. 6:28. doi: 10.3389/ fnbeh.2012.00028

Copyright (c) 2012 Anjum and Brecht. This is an open-access article distributed under the terms of the Creative Commons Attribution Non Commercial License, which permits non-commercial use, distribution, and reproduction in other forums, provided the original authors and source are credited. 